\title{
Effect of Spirulina platensis on the crumb firming of wheat bread during storage
}

\author{
Denka Zlateva ${ }^{1}$, Rosen Chochkov ${ }^{2}$
}

\author{
1 - University of Economics, Varna, Bulgaria \\ 2 - University of Food Technologies, Plovdiv, Bulgaria
}

\section{Keywords:}

Bread

Staling

Algae

Spirulina platensis

Crumb

\section{Article history:}

Received 21.12.2018

Received in revised form 24.06.2019

Accepted 28.11.2019

Corresponding author:

Rosen Chochkov

E-mail:

rosen4o4kov@abv.bg

DOI: $10.24263 / 2304-$

974X-2019-8-4-15

\section{Abstract}

Introduction. The effect of Spirulina platensis on the crumb firmness during storage $(96 \mathrm{~h}$ ) of wheat bread was studied by measuring the deformation properties (total, plastic and elastic deformation).

Materials and methods. Bread is obtained from wheat flour with the addition of Spirulina platensis (powder) in the amount of 2 or $4 \%$ by the weight of flour. The deformation properties of the bread crumb were studied 3 , 24, 48, 72 and 96 hours after the baking. The deformation characteristics of the bread crumb are measured using automatic penetrometer, by immersion of a body with a certain mass for a certain time.

Results and discussion. The highest penetration, and therefore the greatest softness of the bread crumb is found in the bread with the addition of Spirulina platensis in the amount of $4 \%$ by weight of flour. In the both algae samples, the rate of firming of the crumb is slower and after 96 hours of storage the total deformation of the crumb decreases 2.75 times, while that of control sample decreases 3.6 times. Bread samples containing Spirulina platensis have a higher plasticity of the crumb during the whole period of storage (96 hours). Algae addition in the amounts of $2 \%$ and $4 \%$ by weight of the flour leads to an improvement in the plastic properties of the bread crumb and to their retention for a longer time than in the control sample. During storage in the control sample elasticity of the bread crumb gradually decreases and at the last measurement ( 96 hours after baking) it is 3.54 times lower compared to the first measurement $-3 \mathrm{~h}$ after baking. The elasticity of the bread crumb is affected by the addition of Spirulina platensis. Bread samples, which recipe includes 4\% Spirulina platensis have a higher elasticity of the crumb throughout the storage period.

Conclusions. Crumb firmness decreased with the incorporation of Spirulina platensis powder. The addition of Spirulina platensis in the amount of $4 \%$ determines the greatest softness of the bread crumb. 


\section{Introduction}

Bread staling is a process, that occurs during storage period. It is a complex phenomenon that affects the product characteristics by losing freshness in terms of flavour, texture, perceived moisture and other sensory characteristics.

Bread staling has been extensively studied for more than a century. The first research on staling was conducted by Boussingault [1], who pointed out that staling of bread is not due to loss of moisture and that stale bread could be freshened by moderate heating. Later, using X-ray diffraction, Katz [2] showed that crystallization of amylose and amylopectin was responsible for the firming of bread over time. However, despite intensive research efforts of many authors the complete molecular mechanisms for bread staling remain elusive [3].

Nowadays crumb-firming has been widely studied proposing different theories that involve numerous phenomena occurring simultaneously in the bread during storage (e.g. starch retrogradation, a modification of the gluten structure or moisture migration/ redistribution in the crumb) [4]. Different authors [5, 6] suggest that the retrogradation of starch is the main reason for the physico-chemical changes during storage. The retrogradation process occurs when amylose and amylopectin chains realign themselves, converting the gelatinized starch molecules to a more compacted and resistant crystalline form [7]. Other authors also point, that the migration of water molecules plays role to bread staling $[8,9]$. It is well known, that after baking, migration of water occurs from bread crumb to crust due to the moisture gradient. The bread staling process starts along with the loss of moisture initiating the retrogradation of starch [10]. Water migrates from gluten to starch leading to plasticity loss of crumb and eventually to the reduction of molecular mobility. On the other hand, water is redistributed and incorporated in retrograded amylopectin crystals, leading to crumb hardening and bread staling during storage [7].

The mechanisms of action in molecular level of bread staling are still not fully understood. The change of starch in bread plays a crucial role and has been extensively studied [11]. Upon cooling, some starch chains began to reassociate into a different ordered structure $[12,13]$. Studies confirm the central role of amylopectin retrogradation and water redistribution within the different polymers in determining bread staling [14].

Apart from starch and water molecules, gluten is also a factor to affect bread staling. The gluten network in fresh bread is flexible and elastic. It is noteworthy to pinpoint that the gluten network could reduce starch recrystallization, owing majorly to the interaction with starch granules via hydrogen bonds [15].

It can be assumed, that all the various components of bread composition will play a role in bread staling, as they undergo changes during the bread making process and during aging of the final product. Thus, the staling kinetics depend on a complex balance of input parameters (dough ingredients, yeast, enzymes), process parameters (mixing, proofing, baking, cooling) and storage parameters (humidity, temperature). To date, various food additives have been applied to bread and other bakery foods to retard staling.

Nowadays the consumption of marine products is increasingly gaining attention. Edible seaweeds or marine macro algae are one of the richest sources of valuable compounds, which are traditionally consumed by humans as food [16]. In the baking industry, hydrocolloids are of increasing importance as bread making improvers, where their use aims to improve dough handling properties, increase the quality of fresh bread, and extend the shelf life of stored bread [17]. Seaweed polysaccharides are a potential source of soluble dietary fibers. These compounds have higher water holding capacity than cellulosic (insoluble) fibers. Elleuch et al. point out that soluble dietary fibers demonstrate the ability to increase viscosity, form gels and/or act as emulsifiers [18]. 
Most of the authors focus their attention on the increase of nutritional and biological value of the algae-enriched bakery products, there are not enough studies on the textural properties and shelf-life of bread prepared with edible seaweeds. Lee et al. [19] evaluated the shelf-life and quality of breads made with $0.5,1.0$, and $2.0 \%$ of Myagropsis myagroides. It was concluded that the addition of $0.5 \% \mathrm{M}$. myagroides to breads has a good influence on improving the shelf-life and the overall quality of the products. Mamat et al. [17] find out that dried red seaweed species (Kappaphycus alvarezii) at amount 2-8\% influenced dough and bread textural properties.

Bread prepared with the addition of Ahnfeltia had a greater shelf life than the traditional one; changes in the organoleptic and physicochemical parameters of the enriched bread during storage were less noticeable. At the same time, Ahnfeltia had more effective influence on the freshness retention of bread during storage than Costaria, probably due to the fact that in the composition of Ahnfeltia tobuchiensis, agaroids are predominate, they slow down the process of retrogradation of gelatinized starch and eventually prevent intensive staling of bread [20, 21].

However, the impact of algae on the keeping of bread freshness is not discussed extensively. It is worthwhile to find out how they affect the freshness of the bread during storage. The main manifestation of bread staling is crumb firming. Therefore, the purpose of the present study is to investigate the effect of Spirulina platensis on the crumb firmness during storage of wheat bread by measuring the deformation properties.

A number of objective methods can be used to characterize bread freshness:

- Methods based on determining the hydrophilicity of the bread crumb;

- Methods based on the determination of the content of water-soluble substances in the bread crumb;

- Methods based on the determination of the moisture in the bread crumb;

- Methods based on determining the physical properties of the bread crumb (such as firmness, plasticity, elasticity).

According to AACC (1999), bread firmness is defined as the force required to compress the crumb at a fixed distance or to evaluate freshness, defined as the distance that a fixed force will compress a crumb [22].

\section{Materials and methods}

\section{Materials}

For the preparation of the bread samples the following materials were used:

- Commercial wheat flour type 500 with the following properties: moisture content $12.8 \%$; gluten content $-27.07 \%$; release of gluten $-6 \mathrm{~mm}$; titratable acidity $-2{ }^{\circ} \mathrm{H}$;

- Water - according to ISO 6107-1:2004

- Commercial yeast (Lesafmaya);

- Salt - according to Codex Standard for Food Grade Salt CX STAN 150-1985;

- Spirulina platensis powder (average chemical composition: protein $64 \mathrm{~g} / 100 \mathrm{~g}$; fat $8.2 \mathrm{~g} / 100 \mathrm{~g}$ of which saturated $3.42 \mathrm{~g}$; carbohydrates $16.1 \mathrm{~g} / 100 \mathrm{~g}$, of which sugars $0.52 \mathrm{~g}$, fiber $7 \mathrm{~g} / 100 \mathrm{~g})$.

\section{Methods}

Dough and bread composition. The composition of the bread samples is presented in Table 1. 
Bread samples composition

\begin{tabular}{|l|c|c|c|}
\hline \multirow{2}{*}{ Ingredients } & \multicolumn{3}{|c|}{ Bread samples } \\
\cline { 2 - 4 } & $\begin{array}{c}\text { Control } \\
\text { sample }\end{array}$ & $\begin{array}{c}\text { Sample with 2\% } \\
\text { Spirulina platensis }\end{array}$ & $\begin{array}{c}\text { Sample with 4\% } \\
\text { Spirulina platensis }\end{array}$ \\
\hline Wheat flour type 500, g & $\mathbf{2 5 0}$ & $\mathbf{2 4 5}$ & $\mathbf{2 4 0}$ \\
\hline Water, cm ${ }^{3}$ & $\mathbf{1 4 0}$ & $\mathbf{1 4 5}$ & $\mathbf{1 5 5}$ \\
\hline Yeast, g & 3.37 & 3.37 & 3.37 \\
\hline Salt, g & 3.25 & 3.25 & 3.25 \\
\hline Spirulina platensis, g & - & $\mathbf{5}$ & $\mathbf{1 0}$ \\
\hline
\end{tabular}

Bread preparation. Bread is obtained from type 500 wheat flour by a two-phase method. Initially, knead the yeast, flour and water dough in a 1:1 ratio in kneading machine (Labomix 1000, Hungary). Pre-mixed Spirulina platensis algae (powder) in the amount of $2 \%$ or $4 \%$ by the weight of flour are added to the mixing water. The dough thus prepared matures for 4 hours at $33^{\circ} \mathrm{C}$ and then mix the dough to obtain a homogeneous mass by adding the remainder of the flour to the formulation and salt $(1.3 \mathrm{~kg} / 100 \mathrm{~kg}$ flour $)$. The bread dough divides (440 g) and forms, matures for 55 minutes at $38{ }^{\circ} \mathrm{C}$ (Tecnopast CRN 45-12, Novacel ROVIMPEX Novaledo, Italy). After the final fermentation, the pieces of dough were put into an electric oven (Salva E-25, Spain) pre-heated to $200-220^{\circ} \mathrm{C}$. The baking time is $24 \mathrm{~min}$, until the temperature in the center of the bread crumb reach $96-98^{\circ} \mathrm{C}$. After baking, the bread is allowed to cool down for $3 \mathrm{~h}$ at room temperature.

Determination of deformation properties of the bread crumb. The deformation properties of the bread crumb were studied - total, plastic and elastic deformation 3, 24, 48, 72 and 96 hours after the baking. The deformation characteristics of the bread crumb are measured using automatic penetrometer AP-4/2 (Germany), by immersion of a body with a certain mass for a certain time and are expressed in penetrometric units (PU) [23]. The measurement is made on a piece of bread crumb (from the center of the bread) $40 \mathrm{~mm}$ thick. Depending on the size of the test piece, the determination is made at three (or five) locations at least $30 \mathrm{~mm}$ apart from the crust. During the test, bread samples are stored under conditions that do not allow moisture exchange with the environment.

Statistical analysis. All experiments were conducted in triplicate and results were expressed as mean \pm standard deviation. Statistical analysis was carried out with SPSS version 21.0 (SPSS Inc., Chicago, IL, USA). A one-way-analysis of variance (ANOVA) and Duncan's multiple comparison tests were used to determine the significant differences at a level of 0.05 .

\section{Results and discussion}

\section{Effect of Spirulina platensis on the total deformation of bread crumb}

Changes in the texture firmness of Spirulina platensis-enriched and control bread samples over 96 hours of storage are shown in Figure 1. 


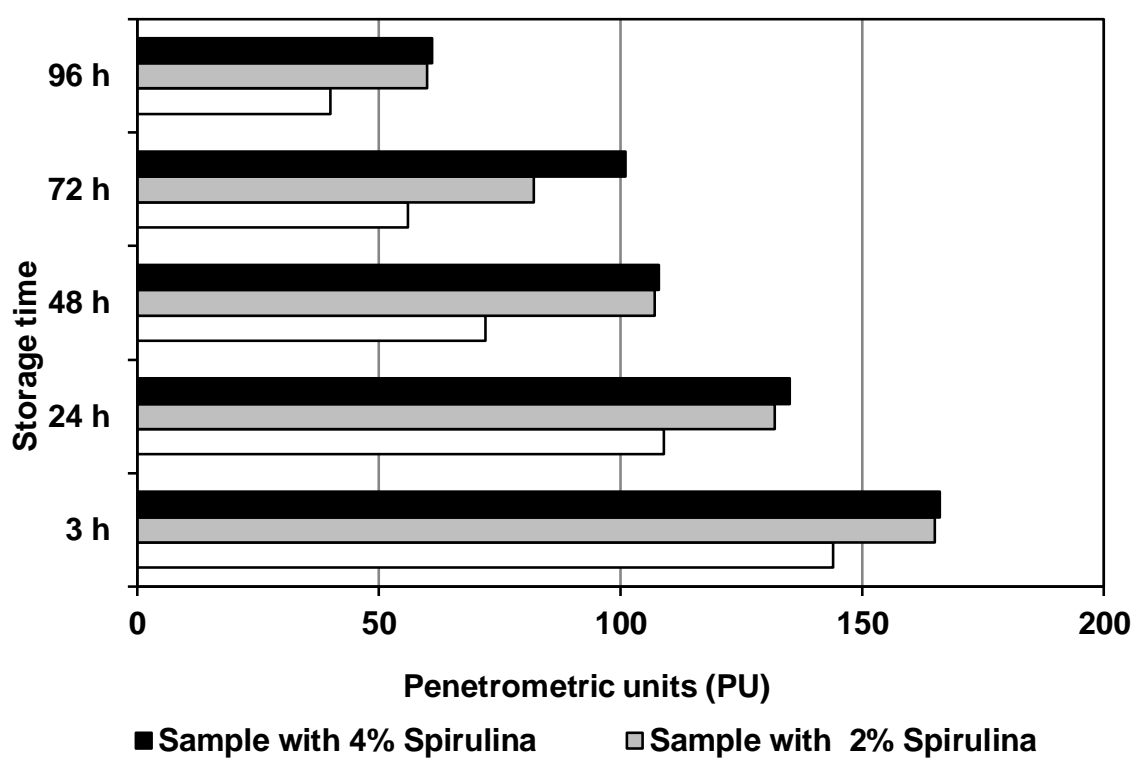

Figure 1. Total deformation of bread crumb (PU)

As can be seen from the figure, in all analyzed samples the total deformation of the crumb is reduced by extending the storage period. The lowest values, irrespective of the duration of storage of the bread $(3,24,48,72$ or $96 \mathrm{~h})$ are measured in the control sample. The highest penetration, and therefore the greatest softness of the bread crumb is measured in the bread, in which formulation Spirulina platensis is included (in the amount of $4 \%$ by weight of flour).

Throughout the period of storage, the crumb of the control sample had the least contractility and therefore - the highest firmness. 3 hours after baking, the total deformation is 144 penetrometric units (PU), which then decreases gradually, which indicates the hardening of the bread crumb. At the end of the storage (after $96 \mathrm{~h}$ ) the total deformation of the crumb of the control sample is 40 penetrometer units (PU), i.e. it has decreased 3.6 times during the storage period. It is noteworthy that the reported values decrease with equal intensity. The bread crumb of the samples with Spirulina platensis is deformed to a greater extent in penetration and therefore features a softness that is retained throughout the period of storage. The amount of algae used (2\% and $4 \%$ ) does not significantly affect the total deformation. Three hours after bread baking, a total deformation of 165 PU is reported in both samples. Throughout the storage period the results for the both samples are quite similar, with only 72 hours after baking, the bread with $4 \%$ Spirulina platensis has a greater softness of the crumb. In the both algae samples, the rate of hardening of the crumb is slower and after 96 hours of storage the total deformation of the crumb decreases 2.75 times. After 48 hours, the algae containing samples have a firmness of the crumb recorded for the control sample after 24 hours of storage. Spirulina platensis contains hydrocolloids [24], and these types of polysaccharides are known to reduce the degree of moisture loss during storage of bakery products, thereby lowering the rate of crumb dehydration and hardening

Different studies have been carried out showing the potential use of seaweed hydrocolloids in the baking industry as an ingredient slowing down bread staling. According 
to Rojas and coauthors [25] hydrocolloids can modify starch gelatinization and extend the overall quality of the product over time [26]. Guarda et al. [27] reported that breads containing hydrocolloids showed a lower loss of moisture content after baking due to higher water retention in the crumb. It is well known that moisture redistribution is one of the factors affecting bread staling and crumb firmness.

\section{Effect of Spirulina platensis on the plastic deformation of bread crumb}

The results obtained by determining the plastic deformation of the bread crumb are presented in Figure 2.

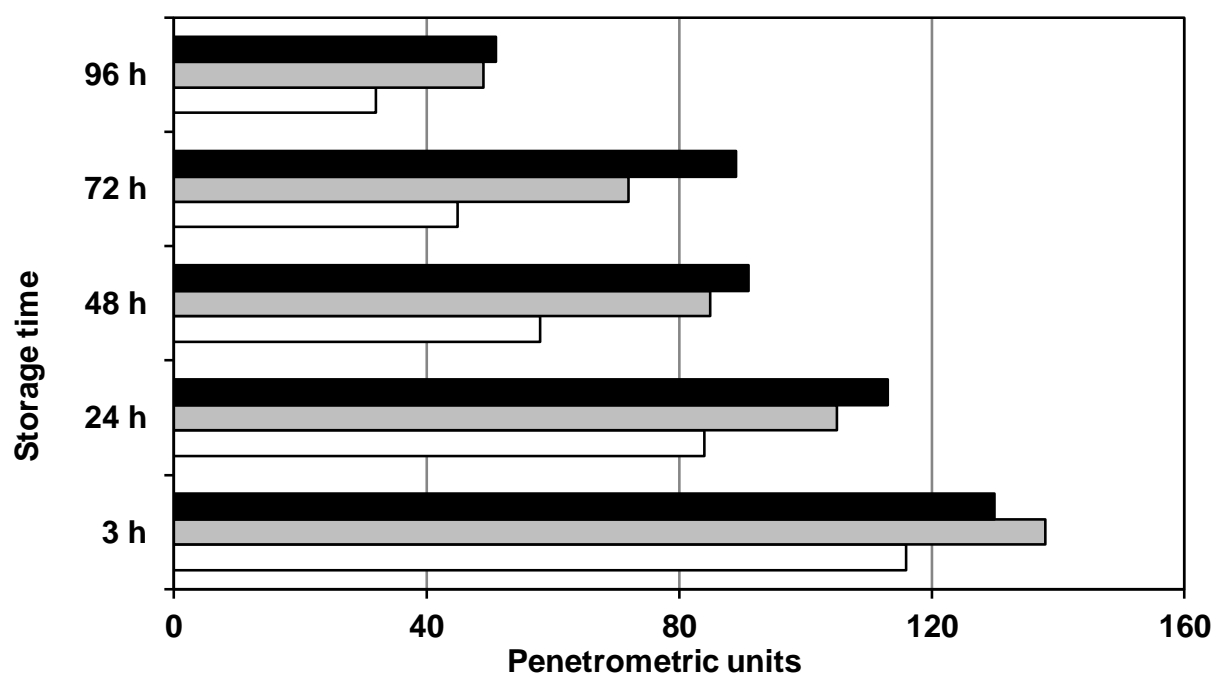

a Sample with $4 \%$ Spirulina $\square$ Sample with $2 \%$ Spirulina $\square$ Control sample

Figure 2. Plastic deformation of bread crumb

Algae containing samples have a higher plasticity of the crumb than the control sample. Regarding the bread with $2 \%$ Spirulina platensis at the beginning of storage, the reported value is $128 \mathrm{PU}$ and is 1.2 times higher than that of the control sample. At the initial measurement (after 3 hours) the bread crumb of the sample with $4 \%$ Spirulina platensis falls behind in terms of its plastic properties in comparison to the bread crumb with $2 \%$ algae, but in the next measurements the sample containing $4 \%$ algae has better plastic properties and this regularity is maintained throughout the storage period. After 96 hours, the difference in plastic deformation of the enriched samples is only 2 PU. Whereas the control sample plastic deformation decreased 3.63 times within the period of storage, then the enriched samples the change was 2.81 times for the bread with $2 \%$ algae and 2.55 times for the bread with $4 \%$ Spirulina platensis.

In the samples prepared with the addition of algae, the bread crumb is distinguished by a higher plasticity and softness which is related to the higher porosity found during the experimental studies - figure 3 . 


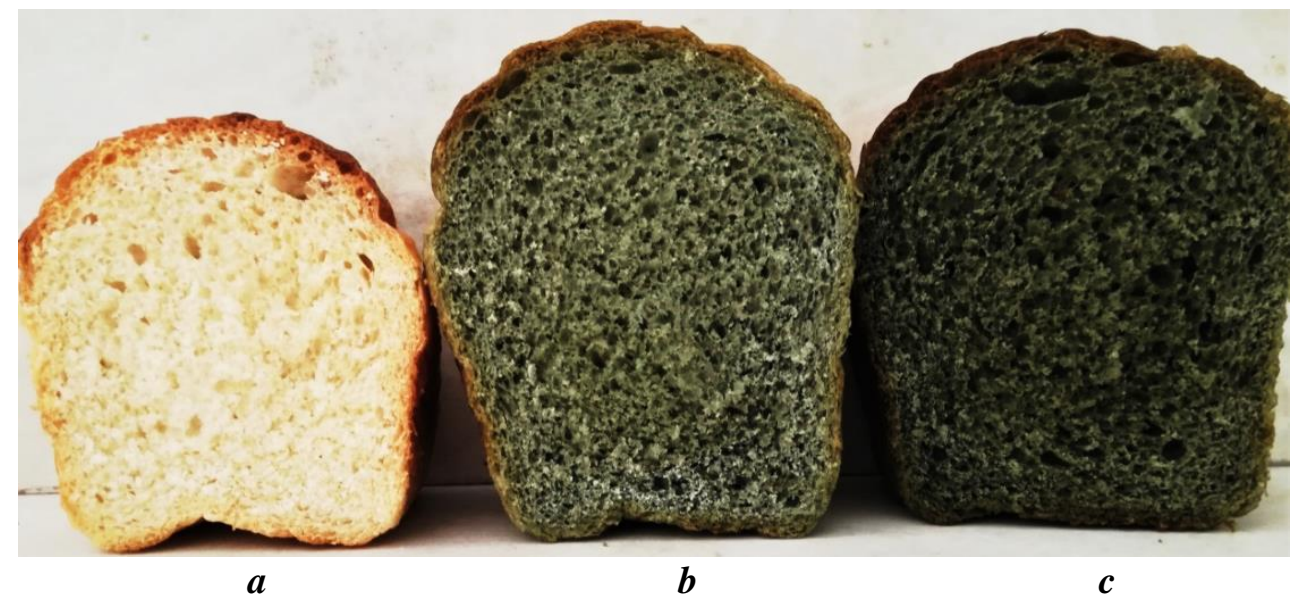

Figure 3. Bread samples tested:

a - control sample; b - sample with $2 \%$ Spirulina platensis;

c-sample with $4 \%$ Spirulina platensis

72 hours after baking the bread with $4 \%$ Spirulina platensis, the plastic deformation value is 2 times higher than that of the control sample, and 1.24 times higher than that of the bread prepared with $2 \%$ algae. This proves that the addition of Spirulina platensis in the amounts of $2 \%$ and $4 \%$ by weight of the flour leads to an improvement in the plastic properties of the bread crumb and to their retention for a longer time than in the control sample.

These results are consistent with those of other researchers who also found that natural hydrocolloids in seaweeds improved dough characteristics and extended bread shelf life, also improve texture of the bread crumb [28]. Arufe and coauthors [29] investigate the effect of brown seaweed powder on physical and textural properties of wheat bread. They emphasize that a maximum of $4 \%$ (flour base) seaweed powder could be added, without impairing the crumb texture of enriched breads. Otherwise, using higher amounts, crumb firmness increases.

\section{Effect of Spirulina platensis on the elastic deformation of bread crumb}

The results obtained by determining the elastic deformation of the bread crumb are presented in Figure 4.

The experimentally established results show that as the bread storage time increases, the elasticity of the bread crumb decreases and this trend occurs in all samples subjected to testing.

During storage for $96 \mathrm{~h}$ in the control sample, the elasticity of the bread crumb gradually decreases and at the last measurement ( 96 hours after baking) it is 3.54 times lower compared to the beginning of storage $-3 \mathrm{~h}$ after baking the product. This is explained by the changes occurring in the starch fraction of the bread, and in particular with retrogradation of the amylopectin. Bread staling is inevitably associated with the deterioration of the structural properties of the bread crumb - reducing the softness and elasticity. 


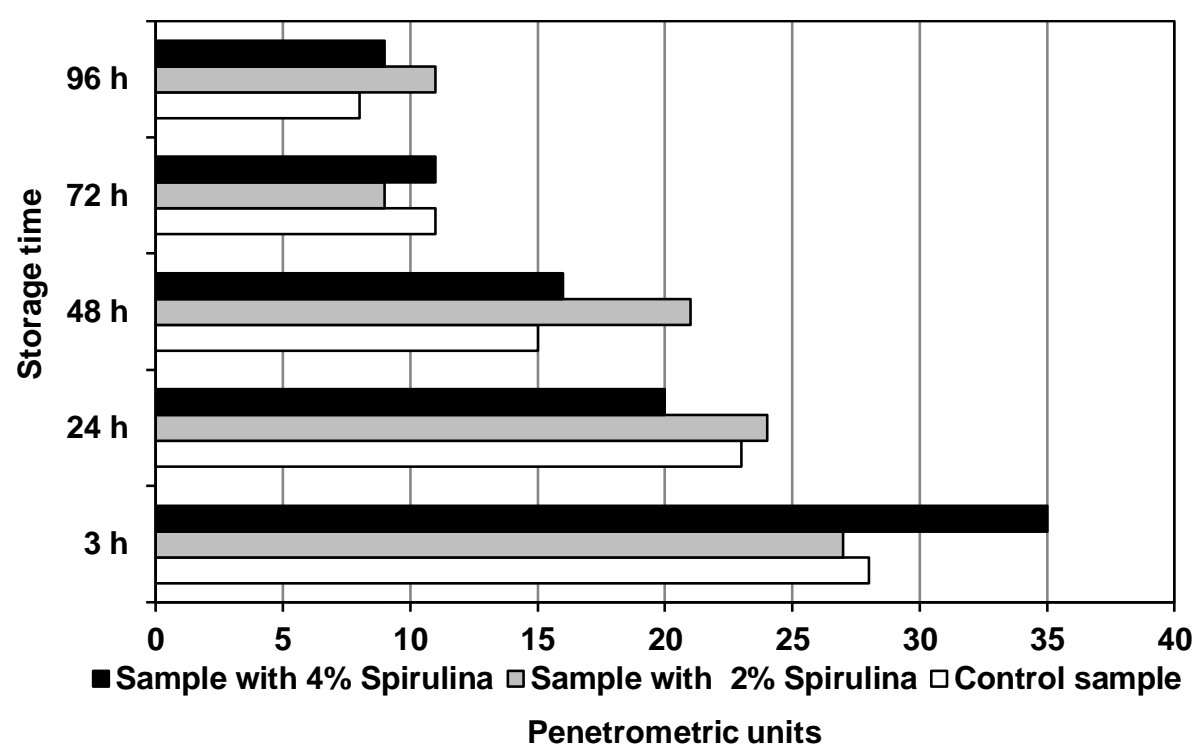

Figure 4. Elastic deformation of bread crumb

The elasticity of the bread crumb is affected by the addition of Spirulina platensis. For the sample with the addition of $4 \%$ algae at the beginning of storage, the value of the elastic deformation is 7 penetrometric units higher than that for the control sample. The values decrease by lengthening the storage period, as a more intensive decrease of elasticity is recorded at the beginning of storage (between the $3^{\text {rd }}$ and $24^{\text {th }}$ hour). The bread samples, which recipe includes $4 \%$ algae are characterized by a higher elasticity of the crumb throughout the storage period.

The results obtained by examining the deformation characteristics of the sample with $2 \%$ Spirulina platensis algae indicate that after 48 hours of storage, the elasticity of the bread crumb is identical to that recorded in the control sample after 24 hours of storage. It is noteworthy that in this sample the elasticity decreases 2.45 times for the whole period of storage (96 hours), while for the control sample - 3.5 times. Furthermore, in the middle of storage (between $24^{\text {th }}$ and $72^{\text {nd }}$ hours), the elasticity decreases at a slower rate than in the other samples.

This gives ground to point out that the samples of bread with the addition of Spirulina platensis retain their elasticity for a longer time and increase the time it takes for the bread crumb to harden. This finding is also supported by results published by other authors. Guarda et al. [27] reported that seaweeds because of the alginates showed an anti-staling effect on bread. The ability of alginates to decrease the staling rate of bread samples is attributed to inhibiting interactions between gluten and starch [30].

\section{Conclusion}

In this study the addition of 2 and 4\% Spirulina platensis powder, as a novel approach of bread preparation, was investigated. Results obtained showed that crumb firmness of the 
bread decreased with the incorporation of seaweed powder Spirulina platensis. The addition of Spirulina platensis in the amount of $4 \%$ determines the highest contractility and therefore the greatest softness of the bread crumb. After 48 hours, the samples containing algae have firmness of the crumb recorded in the control sample after 24 hours of storage. Bread crumb in samples with the addition of Spirulina platensis is characterized by a higher plasticity and softness. This gives ground to conclude that bread samples with the addition of Spirulina platensis store softness and elasticity for a longer time and the firming of the bread crumb occurs more slowly.

\begin{abstract}
Acknowledgements. Authors would like to thank to the Ministry of Education and Science of Bulgaria about the subsidy by Regulation № 3 from 27.11.2015 - in accordance with the Ordinance on the Terms and Procedure for the Evaluation, Planning, Allocation and Expenses of the State Budget Funds for the Financing of the Inherent Research Activities of the State Higher Education Institutions. The acknowledgements are also to the academic management of University of Economics - Varna for the allocations in project NPI-16/2018 "Innovative approaches to increase the quality and biological value of foods".
\end{abstract}

\title{
References
}

1. Boussingault J. B. (1852), Expériences ayant pour but de déterminer la cause de la transformation du pain tendre en pain rassis, Annales de chimie et de physique, 36, pp. 490494.

2. Katz J. R. (1928), The X-ray spectrography of starch and gelatinization and retrogradation of starch in the bread staling process, In R. P. Walton (Ed.), A comprehensive survey of starch chemistry NY, Chemical Catalog Co, pp. 68-76.

3. Gray J. A., Be Miller J. N. (2003), Bread staling: Molecular basis and control, Comprehensive Reviews in Food Science and Food Safety, 2, pp. 1-21.

4. Amigo J. M., Olmo A., Engelsen M. M., Lundkvist H., Engelsen S. B. (2019), Staling of white wheat bread crumb and effect of maltogenic $\alpha$-amylases. Part 2: Monitoring the staling process by using near infrared spectroscopy and chemometrics, Food Chemistry, 297, pp. $1-9$.

5. Goesaert H., Slade L., Levine H., \& Delcour J. A. (2009b), Amylases and bread firming-an integrated view, Journal of Cereal Science, 50, pp. 345-352.

6. Hallberg L. M., Chinachoti P. (2002), A fresh perspective on staling: The significance of starch recrystallization on the firming of bread, Journal of Food Science, 67, pp.1092-1096.

7. Slade L., Levine H., Reid D. S. (1991), Beyond water activity: Recent advances based on an alternative approach to the assessment of food quality and safety, Critical Reviews in Food Science and Nutrition, 30, pp. 115-360.

8. Baik M. Y., Chinachoti P. (2000), Moisture redistribution and phase transitions during bread staling, Cereal Chemistry, 77, pp. 484-488.

9. He H., Hoseney R. C. (1990), Changes in bread firmness and moisture during long-term storage, Cereal Chemistry, 67, pp. 603-605.

10. Zeleznak K. J., Hoseney R. C. (1986), The role of water in the retrogradation of wheat starch gels and bread crumb, Cereal Chemistry, 63(5), pp. 407-411.

11. Tao H., Zhang B., Wu F. F., Jin Z. Y., Xu X. M. (2016), Effect of multiple freezing/thawingmodified wheat starch on dough properties and bread quality using a re-constitution system, Journal of Cereal Science, 69, pp. 132-137. 
12. Wang S. J., Li C. L., Copeland L., Niu Q., Wang S. (2015), Starch Retrogradation: A Comprehensive Review, Comprehensive Reviews in Food Science and Food Safety, 14, pp. $568-585$.

13. Fu Z., Chen J., Luo S. J., Liu C. M., Liu W. (2015), Effect of food additives on starch retrogradation, A review. Starch/Stärke, 67, pp. 69-78.

14. Fadda C., Sanguinetti A. M., Del Caro A., Collar C., Piga A. (2014), Bread staling: Updating the view, Comprehensive Reviews in Food Science and Food Safety, 13, pp. 473-492.

15. Ottenhof M.-A., Farhat I. A. (2004), The effect of gluten on the retrogradation of wheat starch, Journal of Cereal Science, 40, pp. 269-274.

16. Gupta S., Abu-Ghannam N. (2011), Recent developments in the application of sea-weeds or seaweed extracts as a means for enhancing the safety and quality attributes of foods, Innovative Food Science \& Emerging Technologies, 12(4), pp. 600-609.

17. Mamat H., Matanjun P., Ibrahim S., Amin S., Hamid M., Rameli A. (2014), The effect of seaweed composite flour on the textural properties of dough and bread, Journal of Applied Phycology, 26(2), pp. 1057-1062.

18. Elleuch M., Bedigian D., Roiseux O., Besbes S., Blecker C., Attia H. (2011), Dietary fibre and fibre-rich by-products of food processing: Characterisation, technological functionality and commercial applications: A review, Food Chemistry, 124 (2), pp. 411-421.

19. Lee C., Choi J., Song E., Lee S., Kim K., Kim S., Jung J. (2010), Effect of Myagropsis myagroid esextracts on shelf-life and quality of bread, Korean Journal of Food Science and Technology, 42(1), pp. 50-55.

20. Smertina E. S., Fedyanina L. N., Kalenik T. K. (2011), Costaria Costata is a functional component in enriched bakery products, Storage and processing of agricultural raw materials, 3, pp. 71-74.

21. Fedyanina L. N., Smertina E. S., Kalenik T. K., Fischenko E. S., Medvedeva E. B. (2012), Functional foods with BAS on the basis of the hydrobiont of plant and animal origin as functional ingredients, Goods expert of foodstuffs, 4, pp. 17-20.

22. AACC (1999) Approved methods of the American Associations of Cereal Chemists, American Association of Cereal Chemists, St. Paul

23. Vangelov A., Karadhzov G. (1993), Bread and pastry technology - a guide for labratory work, Zemizdat, Sofia.

24. Raposo M. F. J., de Morais R. M. S. C., de Morais A. M. M. B. (2013), Bioactivity and applications of sulphated polysaccharides from marine microalgae, Marine Drugs, 11, pp. 233-252.

25. Rojas J. A., Rosell C. M., Benedito de Barber C. (1999), Pasting properties of different wheat flour-hydrocolloids systems, Food Hydrocoll, 13, pp. 27-33.

26. Rosell C. M., Rojas J. A., Benedito de Barber C. (2001), Influence of hydrocolloids on dough rheology and bread quality, Food Hydrocoll, 15, pp. 75-81.

27. Guarda A, Rosell C. M., Benedito de Barber C., Galotto M. J. (2004), Different hydrocolloids as bread improvers and antistaling agents, Food Hydrocoll, 18, pp. 241-247.

28. Rodge A. B., Sonkamble S. M., Salve R. V., Syed Imran Hasmi. (2012), Effect of hydrocolloid (guar gum) Incorcopration on the Quality Characteristics of Bread, J. Food Process Technol, 3:2.

29. Arufe S., Della Valle G., Chiron H., Chenlo F., Sineiro J., Moreira R. (2018), Effect of brown seaweed powder on physical and textural properties of wheat bread, European Food Research and Technology, 244, 1, pp. 1-10.

30. Davidou S., Le Meste M., Debever E., Bekaert D. (1996), A contribution to the study of staling of white bread: effect of water and hydrocolloid, Food Hydrocoll, 10, pp. 375-383. 